\title{
Fill design and implementation with challenging material - Wambo fill project - case study
}

\author{
M Helinski Outotec Pty Ltd, Australia \\ MB Revell Outotec Pty Ltd, Australia
}

\begin{abstract}
Peabody Energy is the world's largest private sector coal company and a global leader in sustainable mining and clean coal solutions. The company serves metallurgical and thermal coal customers in more than 25 countries on six continents and has mining operations across Queensland and New South Wales. Peabody's Wambo Coal Mine is a longwall mining operation located in the Hunter Valley Region of NSW, Australia. Longwall mining activities are ongoing in the Wambo coal seam. Overlying a section of the underground operations (at the surface) is an alluvial channel that hosts an important water course for the area. Abandoned 'board and pillar' workings exist approximately half way between the Wambo seam and the surface. These workings (referred to as the 'Homestead workings') are within the Whybrow seam and when previously mining this area very poor ground conditions were experienced.

Peabody identified a risk of sink holes forming, between the Homestead workings and the surface, during longwall extraction of the underlying section of the Wambo seam. The perceived sinkhole formation was recognised as having the potential to 'break' the surface aquifer, resulting in a significant environmental impact as well as jeopardising the safety and productivity of the longwall operations. This paper presents the design and implementation of a novel cost effective strategy for filling these workings.

The old workings in the Whybrow seam, requiring fill, consisted of approximately $15 \mathrm{~km}$ of roadway, spread over an area of approximately three hectares, involving more than 100 boreholes. The most appropriate material available onsite was a natural alluvial soil. However, the variable nature of this material presented a number of challenges Furthermore, the fill material was to be exposed to a unique set of loading conditions. This paper details test work and analysis strategies employed to ensure that the fill requirements were satisfied. The results are then converted into a flexible framework that facilitates cost effective filling, while ensuring that the design requirements are maintained for the range of different fill source materials.
\end{abstract}

Finally, this paper describes the implementation of the fill solution, presenting useful data collected during the operation and highlighting aspects of the project that worked well and those that posed additional challenges.

\section{$1 \quad$ Introduction}

Peabody's Wambo Coal Mine is a longwall mining operation located in the Hunter Valley Region of NSW, Australia. Longwall activities are ongoing in the Wambo seam. Approximately half way between longwall panels 7 and 8 (of the Wambo seam) and the surface are old 'board and pillar' workings in the Whybrow seam (referred to as the 'Homestead workings'). During mining of the Homestead workings problematic ground conditions were experienced with regular ground falls and, in some cases, the formation of a surface sinkhole, due to intersection roof collapse. The proximity of these workings to longwall panels seven and eight is illustrated in the plan and long sections shown in Figures 1 and 2, respectively.

Overlying almost the entire region shown in Figure 1 (at the surface) is an alluvial channel (aquifer) that hosts an important water course for the area. 


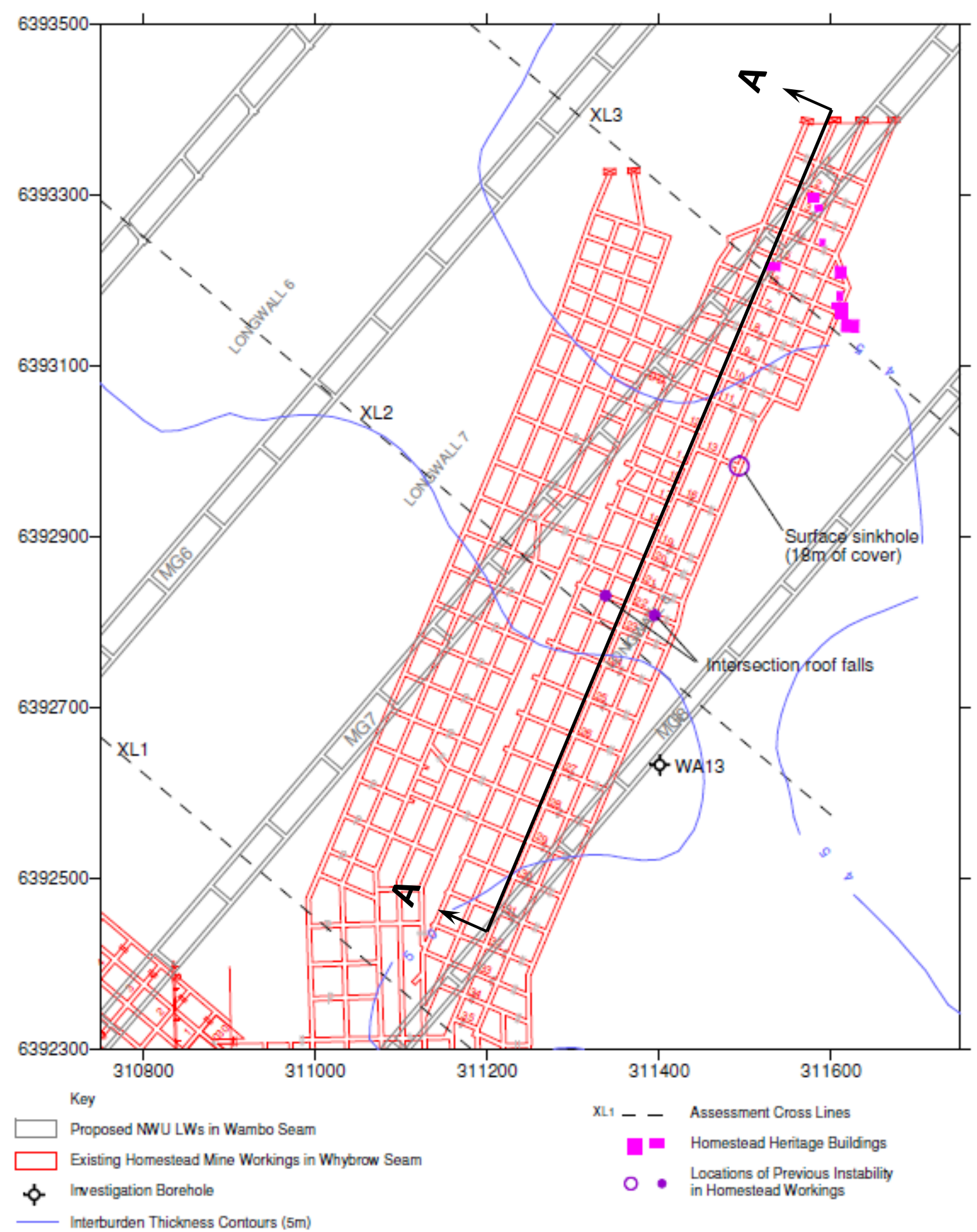

Figure 1 Plan view showing existing Homestead workings and Wambo seam mining plan (provided by Ditton Geotechnical Services) 


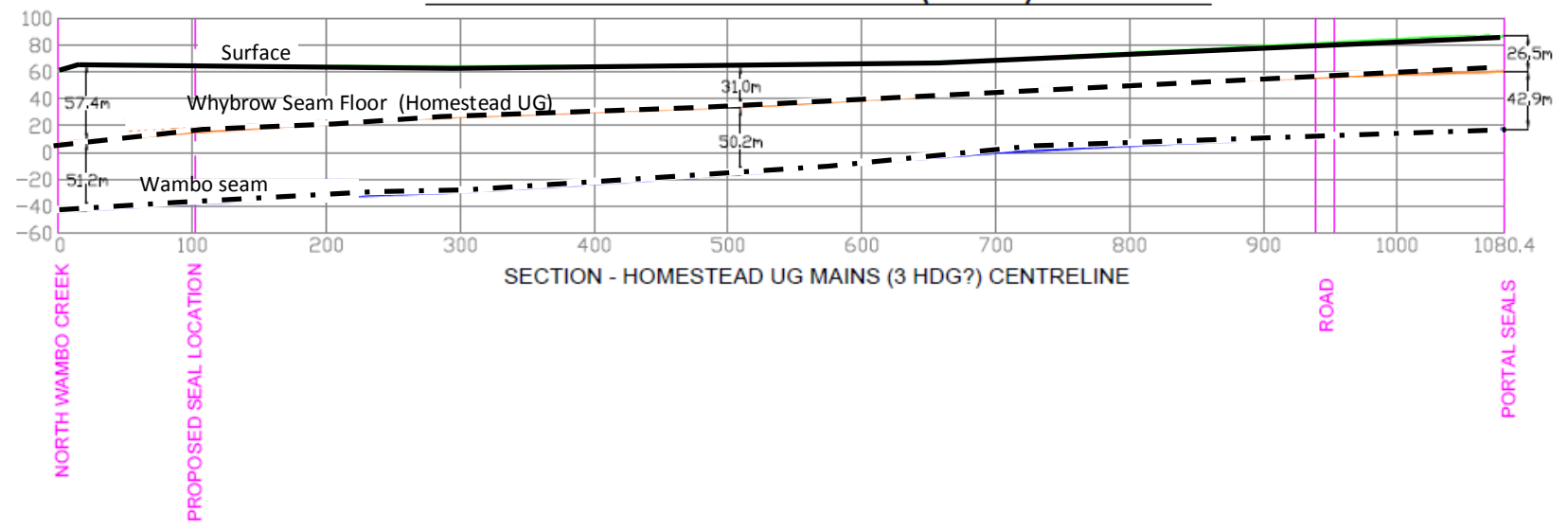

Figure 2 Long section through Section A-A of Figure 1 (provided by Peabody)

During longwall mining, vertical overburden stress is redistributed ahead of the longwall face resulting in an increase in pillar stress through this region. Considering the poor ground conditions, which had been observed above the Homestead workings, Peabody identified that this mining induced stress had the potential to create roof instability, which could create significant sinkholes that extend from the Homestead workings through to the surface.

Due to the presence of the overlying alluvial channel, sinkhole formation had the possibility to create significant groundwater inflow to the underground mine. In addition, diversion of this important water course would have significant environmental consequences.

To manage this risk Peabody chose to backfill the Homestead workings. The Homestead workings that required filling consisted of approximately $15 \mathrm{~km}$ of roadway spread over an area of approximately three hectares. Almost the entire Homestead roadway network presented in Figure 1 required filling. Approximately $250,000 \mathrm{~m}^{3}$ of fill was required through over 100 boreholes. These boreholes were to be lined with $125 \mathrm{~mm}$ NB PVC casing that extends approximately 25-50 m vertically into the Homestead workings.

This paper presents the design and implementation of a robust cost effective strategy for completing this task. The paper discusses novel strategies used to develop the fill system, unique aspects relating to the fill mix design and operational experiences.

\section{$2 \quad$ Fill system}

Like most mine backfill situations, when developing the backfill strategy for the Wambo project the main drivers were material availability, geometry of the region to be filled and the (small) total fill volume required. This section explains the fill solution considered to be most appropriate for the Wambo situation.

\subsection{Material selection}

One of the major costs associated with this project relates to sourcing suitable fill material and costs associated with adequate stabilisation of this material once deposited into the workings. In an effort to identify a superior fill source a number of possible alternatives were considered. These included mine rejects, crushed sandstone and local alluvial soils. Test work was undertaken on each of these material alternatives to assess the expected performance in terms of flowability and the ability to cost effectively achieve acceptable stability once in place. In summary the results showed that:

- The mine rejects had a clay content that was in excess of $50 \%$, resulting in poor flowability, poor consolidation characteristics and the need for high binder addition for stabilisation after deposition. 
- The crushed sandstone presented a superior material consistency, however this material was extremely fine. In a dry state this material was expected to create dust issues and once wet this material becomes very sticky to handle (and manufacture paste) and extremely slippery for equipment working in the vicinity. In addition this material had poor rheological characteristics, meaning that it would have to be deposited at very low solids concentrations.

- Test work on the locally available alluvial soils showed that, if harvested correctly, this material had a favourable particle size distribution (PSD) and mineralogy. Consequently, this material could be transported at high solids concentrations, and when combined with a binder, provided good strength. The drawback with this material was its variable nature and consistent productivity could only be achieved by a fill system suitable for managing variable material.

To investigate the alluvial soil source an intensive test pit campaign was undertaken. An aerial photograph showing the location of the test pits around the site is presented in Figure 3. Based on the results of test work described in this paper, the alluvial deposit was divided into 'North-West' and 'South-East' regions. The outline of these areas is indicated by dotted boundaries in Figure 3 .

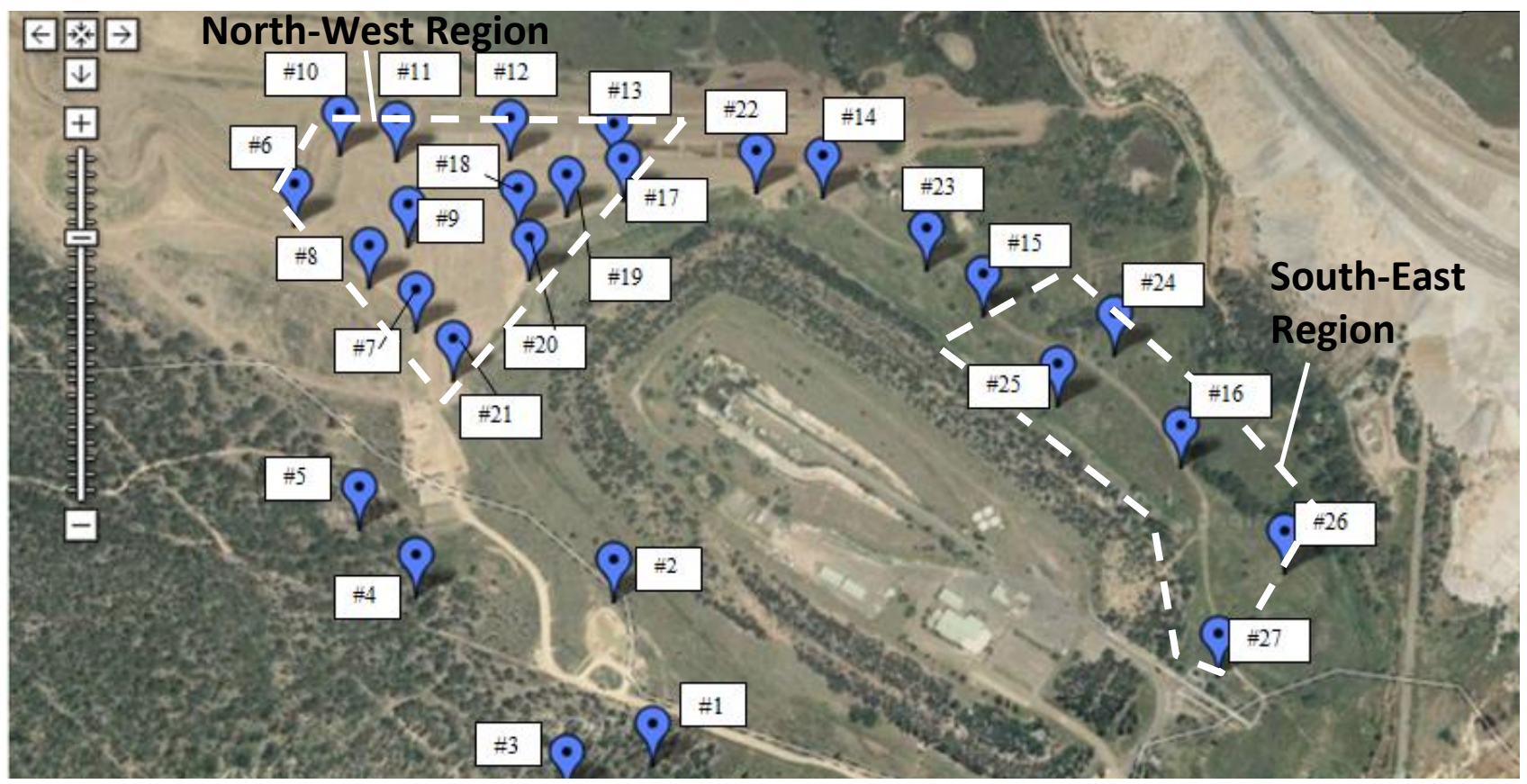

Figure 3 Aerial photograph of alluvial area test pit locations (from Google Maps)

Across the range of test pit locations samples were collected for characterisation test work, which included PSD analysis and mineralogical characterisation in addition to rheological test work. Results from PSD analysis are presented in Figure 4, while Table 1 presents a summary of the key mineralogical components from a range of test pits.

The results presented in Figure 4 and Table 1 show that the PSD and mineralogy of the alluvial material varies considerably across site. These results also show that the region denoted 'North-West' has significantly more fines and clay minerals than material from the 'South-East' region.

Figure 4 also shows that some samples contain a high portion of aggregates greater than $10 \mathrm{~mm}$. It should be noted that prior to sieve analysis all $+20 \mathrm{~mm}$ material were removed from the samples as this was considered necessary to prevent borehole blockages with the $125 \mathrm{~mm}$ NB borehole casing.

To assess the rheological properties conical slump testing was undertaken on a range of different test pit samples. Results from this work are presented as conical slump against mix solids content in Figure 5. 


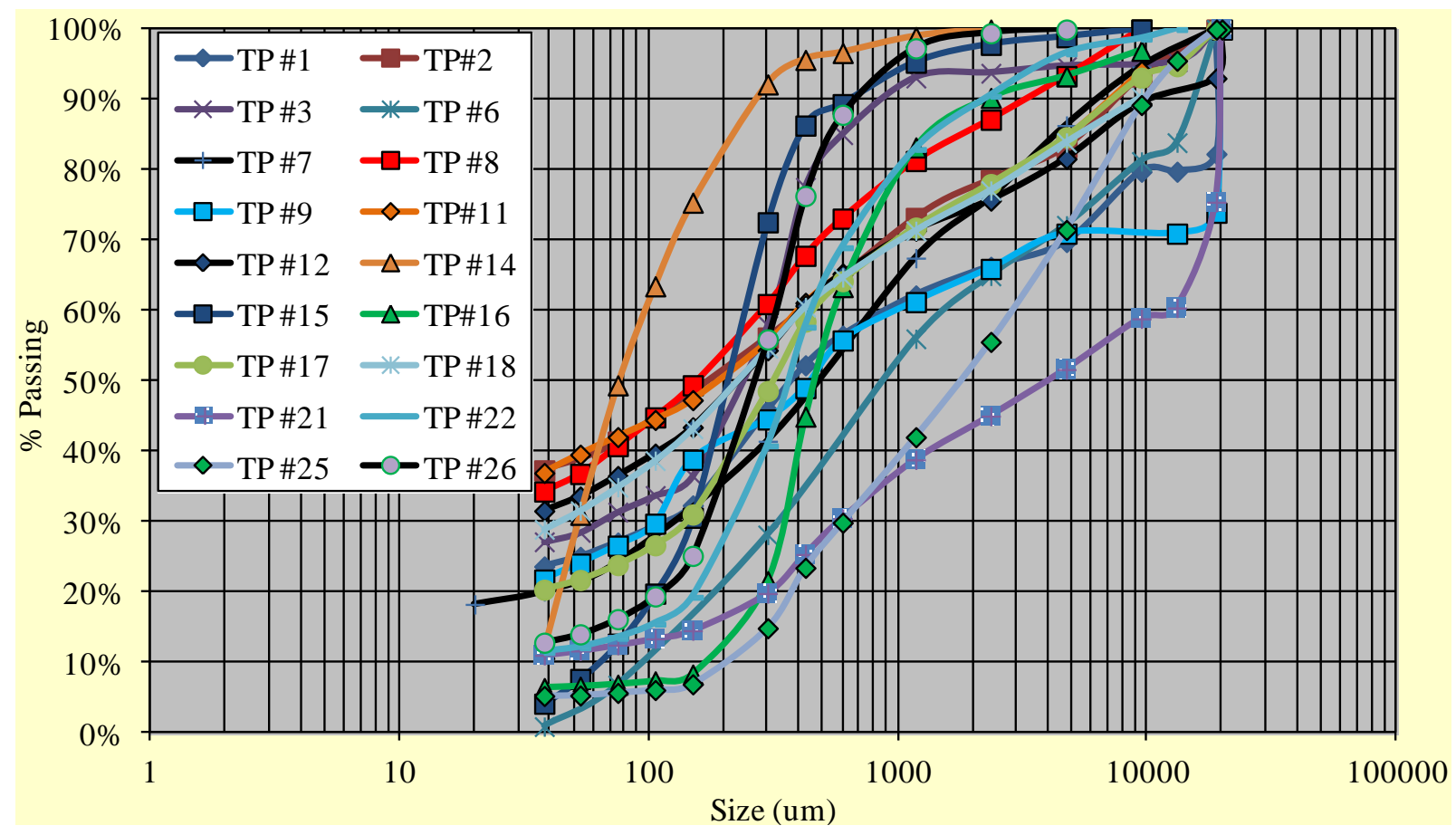

Figure 4 PSD analysis of material samples collected across the alluvial source area

Table 1 Important mineralogical content across alluvial source area

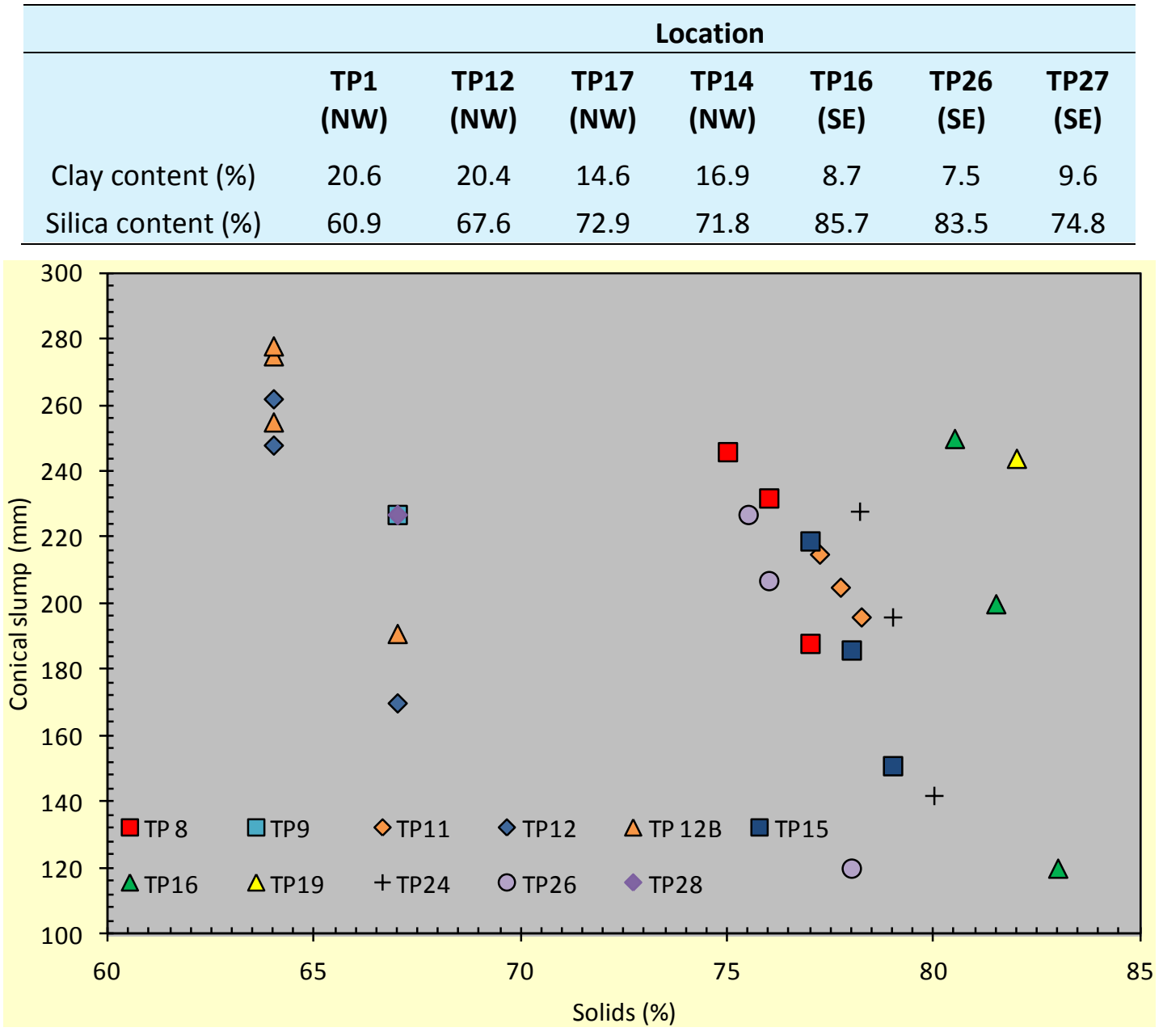

Figure 5 Conical slump against mix solids content for Wambo alluvial samples 
The most notable features of the results presented in Figure 5 are:

- For a given solids content the flowability of the paste varies significantly across the source area.

- Compared with typical relationships for mine tailings, the flowability of some materials are very sensitive to changes in solids contents.

Based on the variability in rheological characteristics, the high sensitivity of the material to changes in solids content and the significant coarse aggregate content, control of a hydraulic delivery system (positive displacement pumping), from a fill plant with a fixed location, was considered impossible to manage. The only practical solution was considered to be a mobile paste plant that could be placed directly above each borehole when filling.

\subsection{Paste plant}

A roadway grid was required immediately above the Homestead workings, to enable drilling of the fill holes. The objective of the plant design was to ensure that the fill plant could be safely moved around this roadway network and be quickly established and remobilised between boreholes. An elevated photograph showing the roadway network, constructed on the surface over the Homestead workings, is presented in Figure 6.

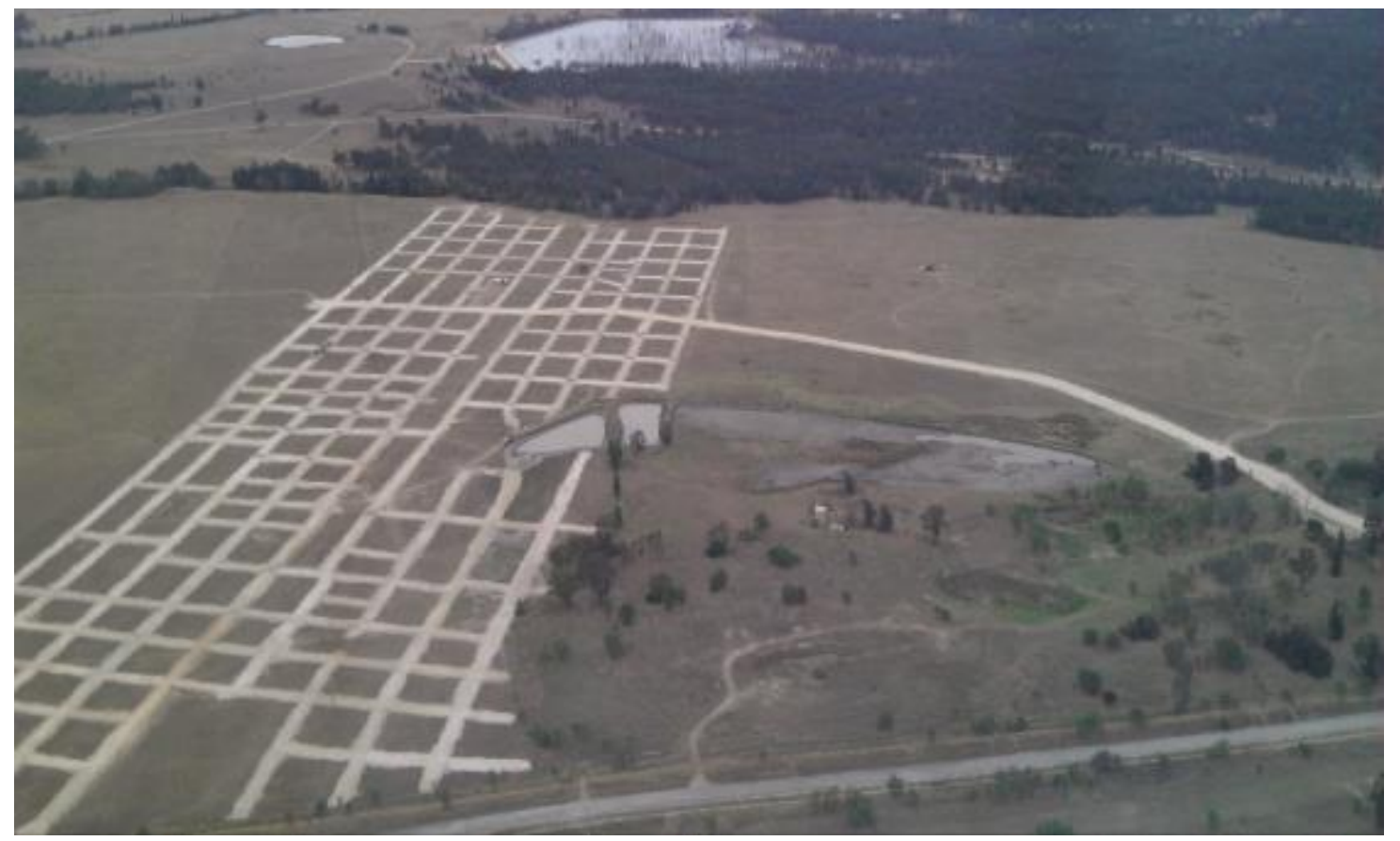

Figure 6 Roadway network over the Homestead workings

The paste plant designed to deliver these requirements involved a twin trailer mobile paste plant as shown in Figure 7. This system consists of a front trailer, which housed the tailings feed hopper, main conveyor system with weightometer, mixer and hopper, while the second trailer housed a generator and cement silo.

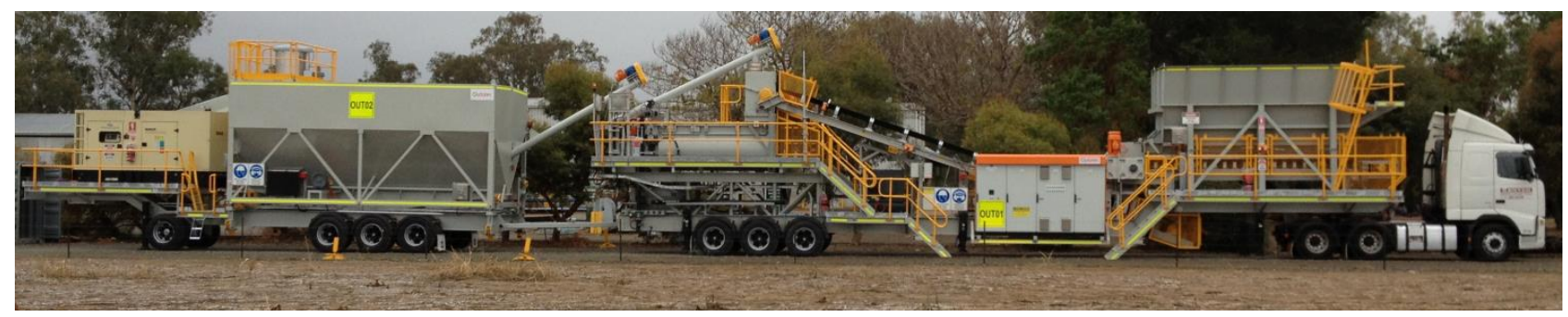

Figure 7 Outotec mobile paste plant 
Figure 7 shows the plant being fed using an excavator driven mobile integrated screening unit (MISU). For the majority of the project this was the hopper feed strategy as it eliminated the need to construct a loader ramp at each borehole. However, where material had a high clay content, MISU processing rates constrained production and it was necessary to screen material independently of filling operations and use a wheeled loader to feed the plant.

This plant is a completely mobile paste plant capable of achieving production rates in excess of $120 \mathrm{~m}^{3} / \mathrm{h}$.

\section{$3 \quad$ Mix design}

\subsection{Design requirements}

As illustrated in Figure 8, the longwall mining process involves the progressive extraction of a horizontal seam, while allowing the rock mass behind the longwall supports to collapse into the 'gob' (or goaf) area.

Collapse of the rock mass behind the longwall increases the stress transferred ahead of the mining face. When the stress increases in front of the longwall face the pillars become loaded, which promotes roof buckling. This initiates rock mass unravelling, which, in the Homestead workings is where 'sink hole' formation is most likely. To arrest sinkhole formation it is necessary that the paste has sufficient stiffness and bearing capacity to support any roof failures.

As the longwall passes the fill material, and the surrounding rock mass unravels, it collapses into the area denoted 'gob' in Figure 8. During this process the fill is expected to be exposed to a range of different stress paths. Should the fill material remain in a saturated state at a sufficiently low density, the fill could potentially liquefy and remobilise into the underlying workings during this stage. Therefore, it is necessary to ensure that the fill material cannot remobilise to eliminate this risk.

This section outlines test work and analysis undertaken to develop a paste fill mix design to satisfy these requirements.

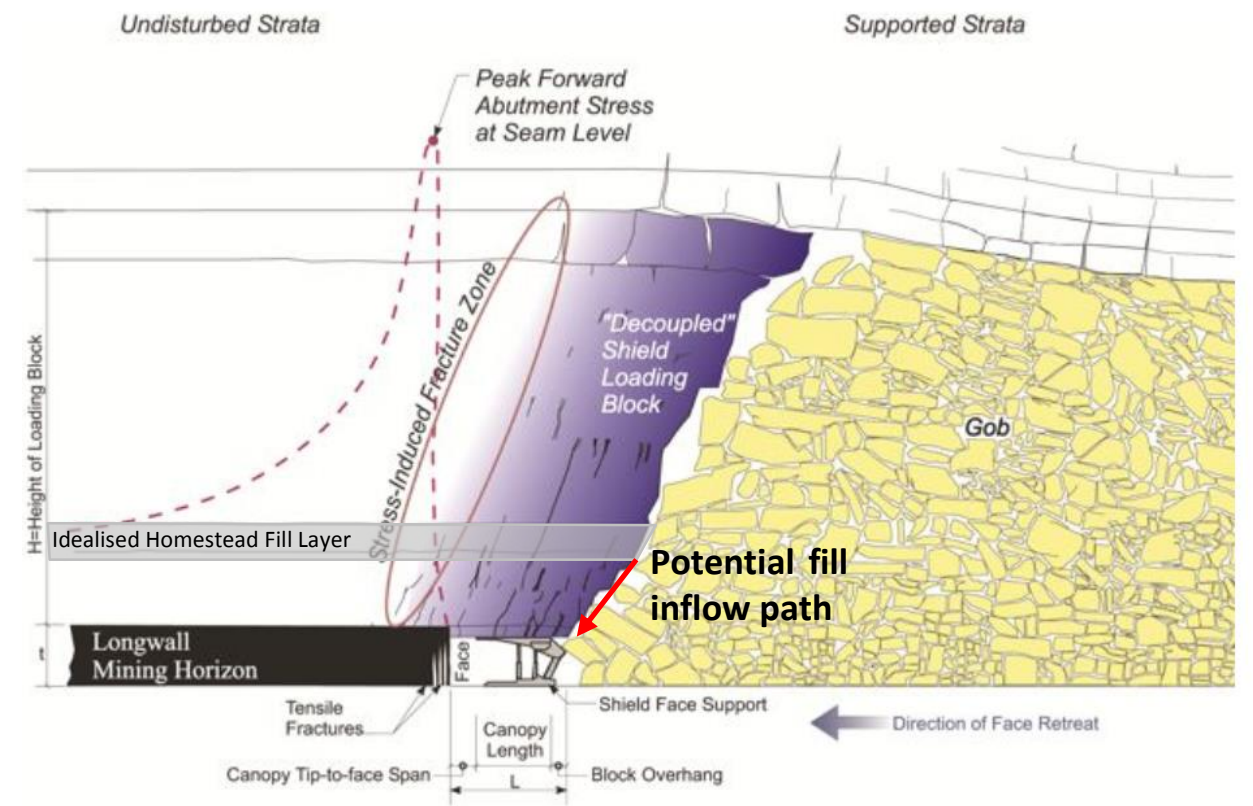

Figure 8 Long section showing the longwall mining process and how this impacts on fill stability (original figure taken from Agapito Associates Inc.)

\subsection{Paste 'flow' risk}

As described by Kramer (1996) liquefaction can be classified in two ways, cyclic mobility and 'flow' liquefaction. Cyclic mobility is the case where saturated soil experiences an increase in pore water pressure through cycles of shear stress, which result in removal of effective stress and strength. 'Flow' liquefaction is 
a large-strain shearing event where monotonic shearing of a saturated soil results in an increase in pore water pressure that exceeds the total stress removing any effective stress. This mechanism is described in more details in Kramer et al. (1996) and Fourie et al. (2001).

For the Wambo filling project, it is considered unnecessary to design the fill mass to resist cyclic mobility as in situ liquefaction would be unlikely to result in adverse consequences. It would only be the case where this material could subsequently flow that would pose a risk to the underground operations. Therefore, it was only necessary to design a fill mass that was resistant to 'flow' liquefaction. As described by Zhang and Garga (1997), material that strain-hardens during continuous undrained loading cannot flow and would therefore be considered resistant to 'flow' liquefaction and suitable.

The ability for soil to strain-harden under undrained shearing comes about due to a tendency for the material to volumetrically expand upon 'drained' shearing (dilate). Methods that can practically be used to achieve a strain hardening paste fill include increasing the mix solids content (leading to increased in situ density) and binder addition. Laboratory testing was undertaken specifically to identify:

1. The mix solids content required to create a strain-hardening paste in situ (i.e. after consolidation).

2. For cases where this solids content cannot be achieved, the combination of binder addition and mix solids content required to cause the material to become strain-hardening.

\subsubsection{Uncemented paste requirements}

\subsubsection{Direct shear testing}

As the intention was to determine the solids concentration that the material would have dilative tendencies upon shearing, direct shearing was adopted as the preferred screening test method. While this method obviously doesn't represent 'undrained' shearing it can be used to identify volumetric changes during shearing and therefore provide an indication of the likelihood of strain-hardening upon undrained shearing. Furthermore, as noted by Been and Jefferies (1985) the sample preparation technique can influence liquefaction susceptibility, and the direct shear apparatus allows paste samples to be prepared as a slurry and poured directly into the box frame in a manner similar to the paste deposition process. This simplified and accelerated the test regime allowing experiments to be undertaken on a range of different alluvial sources. After direct shear testing the mix design was verified through consolidated undrained triaxial testing, as discussed in Section 3.3.1.1.

Testing was undertaken on samples that had been consolidated to a vertical effective stress of $30 \mathrm{kPa}$, as this was considered representative of the vertical effective stress in $3 \mathrm{~m}$ high drive. Examples of the results from direct shear testing are presented in Figure 9. This figure shows the vertical displacement against horizontal displacement for samples from the North-West and South-East regions.

Figure 9 shows that paste batched with a solids content of less than $80 \%$ solids contracted upon shearing, indicating susceptibility to 'flow' liquefaction. Material batched to more than $81 \%$ solids dilated upon shearing, which suggests resistance to 'flow' liquefaction. This outcome appeared consistent for material from both the South-East and North-West regions. 


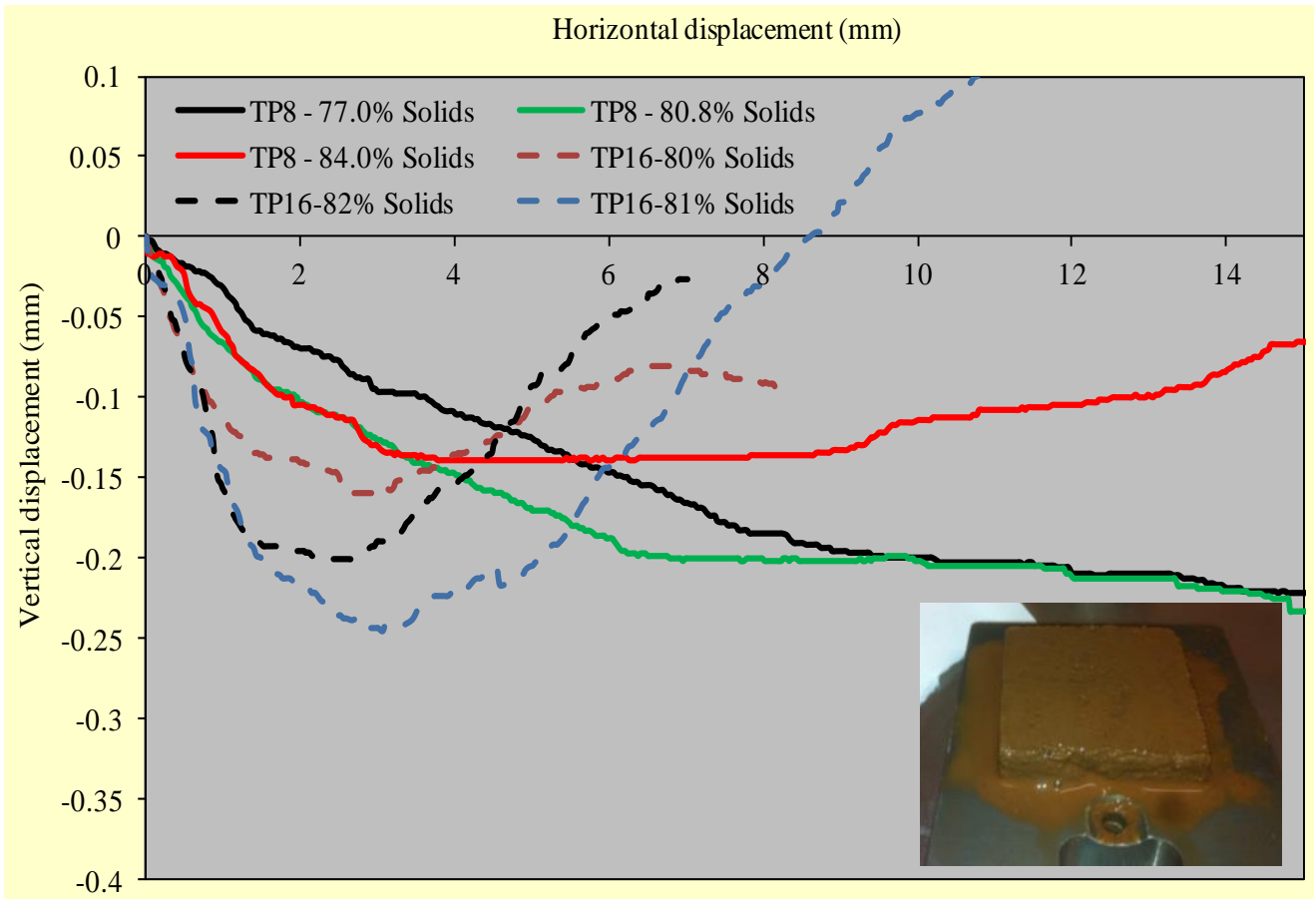

Figure 9 Volumetric changes during direct shear testing

\subsubsection{Consolidated undrained (CU) triaxial testing - uncemented paste}

To confirm the results of the direct shear test work, when subject to undrained shearing, CU triaxial testing was undertaken. The test work procedure used to create these samples was to batch the samples as a paste and pour this material into a split mould, lined with a triaxial membrane, which was mounted on the triaxial pedestal. The top cap was then applied and o-ring fitted, before applying a vertical consolidating stress, of nominally 20-25 kPa through 'dead weights'. The base drainage valve was then opened and a small backpressure was provided to maintain saturation. After initial consolidation the backpressure valves were closed before removing the consolidating weights and then the split mould. The triaxial cell was then carefully built around the specimen prior to imposing an isotropic consolidating stress of $30 \mathrm{kPa}$. This stress was considered representative of the maximum horizontal effective stress for saturated paste in the $3 \mathrm{~m}$ high Homestead workings. After consolidation the specimen was sheared undrained.

The results of CU triaxial testing on a range of paste mixes made from North-West and South-East region alluvials are presented in Figures 10. These figures show the stress path followed during undrained shearing as mean stress ( $p^{\prime}$ ) against deviator stress (q), in Cambridge stress space. The white symbols represent the 'critical state' point (i.e. where the effective stress remained constant at the completion of shearing).

All specimens prepared from the North-West region alluvials, which were batched to less than $78 \%$ solids, strain-softened during undrained shearing. Specimens manufactured from the South-East region alluvials were shown to strain-soften if batched to less than $80 \%$ solids and strain-harden if batched to greater than $80.7 \%$ solids.

Interestingly, both the 'drained' direct shear test work and CU triaxial tests showed the material change from contractive to dilative (or strain softening to strain hardening) at the same mix solids content.

The results of this test work indicate that paste batched to in excess of $81 \%$ solids could be safely deposited into the Homestead workings without any further stabilisation. However, paste deposited at a lower solids content posed a potential risk of 'flow' liquefaction and consequently needed to be stabilised in another way. 


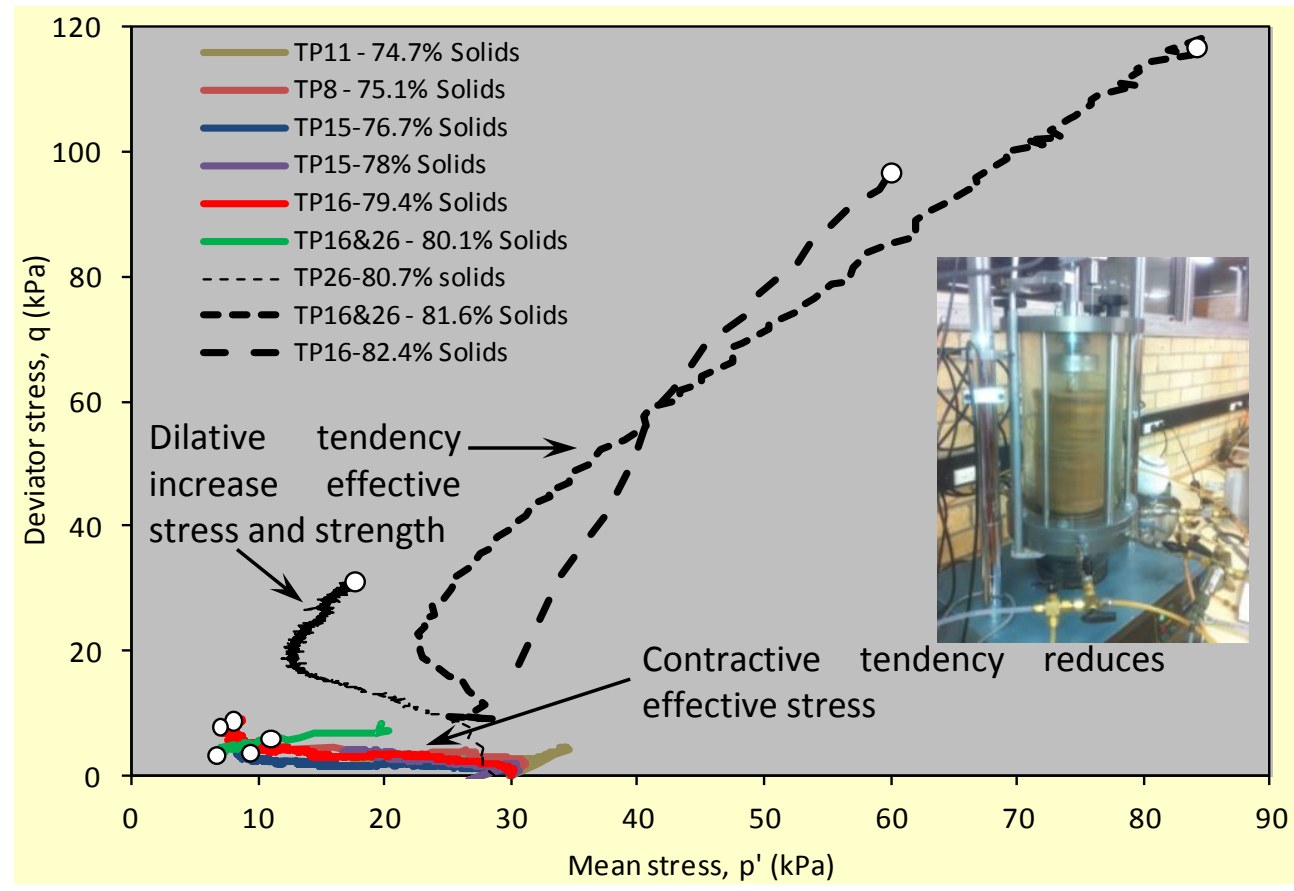

Figure 10 Stress path followed during undrained shearing of uncemented alluvial soil paste

\subsubsection{Cemented paste}

To investigate the binder addition necessary for the stabilisation of Wambo paste, test work was initially undertaken to determine the minimum binder content required to achieve a tangible bond strength considering the influence of binder types, mix solids content and material source on the strength requirements. The results of these tests showed that low heat (LH) cement provided superior strengths to General Portland cement and locally available fly ash blends.

Based on a comprehensive series of paste mixes and unconfined compressive strength (UCS) testing Figure 11 was generated, which shows the mix solids content and LH cement content required to achieve different strength categories. The data presented in Figure 11 was divided into groups of strength ranges.

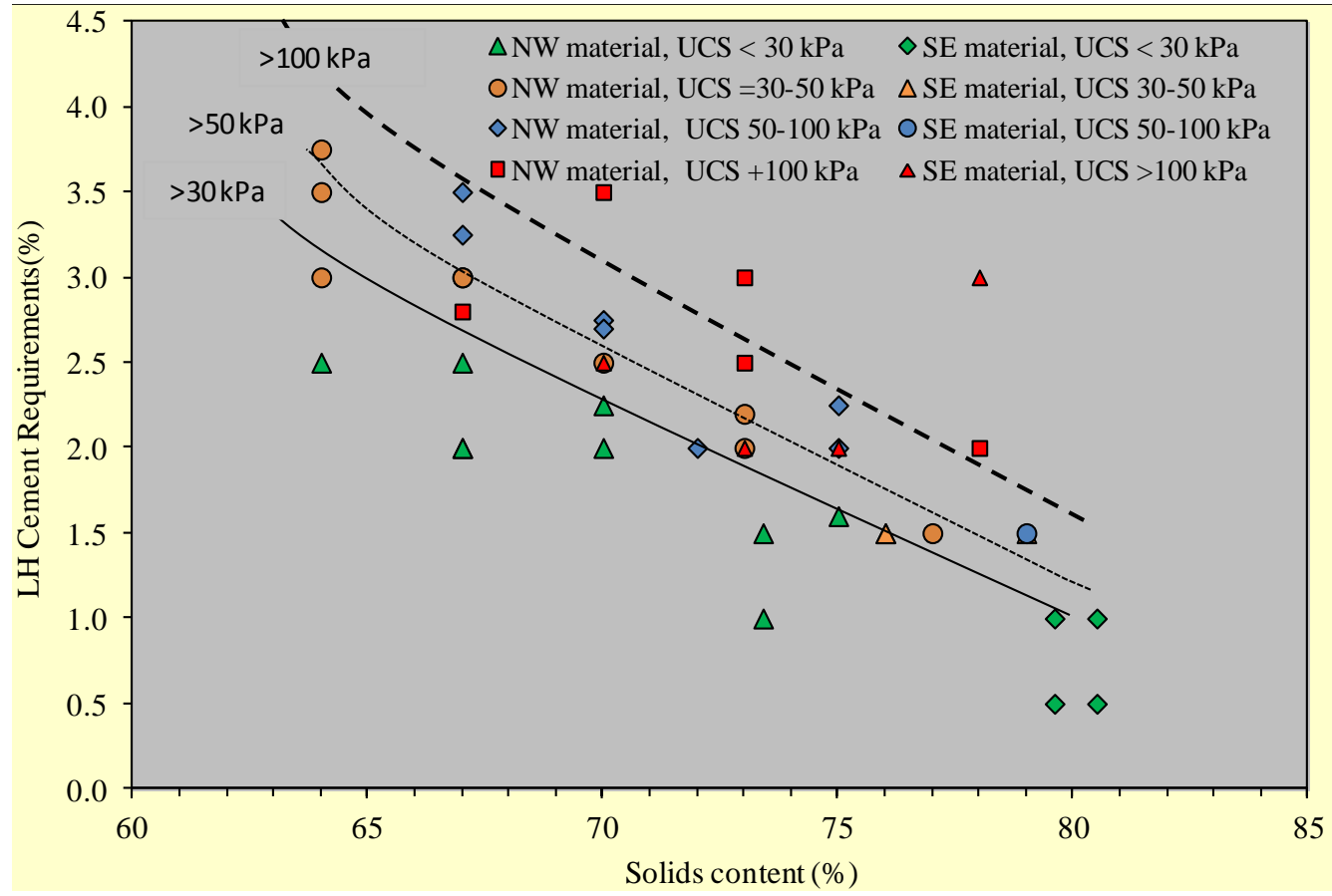

Figure 11 Strength category achieved by a range of different Wambo paste mix combinations 
Superimposed over the data, in Figure 11, are best fit curves developed to bound data for different strength categories. Symbols denoted NW contained material sourced from the North-West area while those denoted SE represented paste manufactured from South-East region material.

Figure 11 indicates that, over the range tested, paste manufactured from both North-West and South-East region material shows a relatively consistent relationship between mix inputs and strength category.

Using the results presented in Figure 11 a campaign of consolidated undrained triaxial testing was undertaken to determine if any of the presented strength categories could be used to identify a (strength based) region where the paste was shown to strain harden under undrained shearing.

Mixes tested as part of this study included both South-East and North-West region alluvials batched to a range of binder and solids contents. All specimens were cured for 28 days prior to testing. Each specimen was isotropically consolidated to an effective stress of $30 \mathrm{kPa}$ prior to undrained shearing.

The stress path followed during undrained shearing is plotted (in Cambridge stress space) in Figure 12. This figure presented the change in mean effective stress $\left(p^{\prime}\right)$ and deviator stress ( $q$ ) throughout shearing. The mix inputs and measured UCS of a corresponding specimen is presented in the legend. White symbols represent the point where each test reaches 'critical state' (i.e. no further change in effective stress with ongoing shearing).

The results presented in Figure 12 show that all cemented specimens dilated upon undrained shearing. These results provide confidence that all Wambo paste material with a UCS in excess of $30 \mathrm{kPa}$ is expected to be resistant to 'flow' liquefaction and would therefore provide a safe solution for the Homestead filling activities. Considering the variability in material characteristics and the resulting variability in material strengths a target paste strength of $50 \mathrm{kPa}$ was considered appropriate to mitigate the risk of 'flow' liquefaction at Wambo.

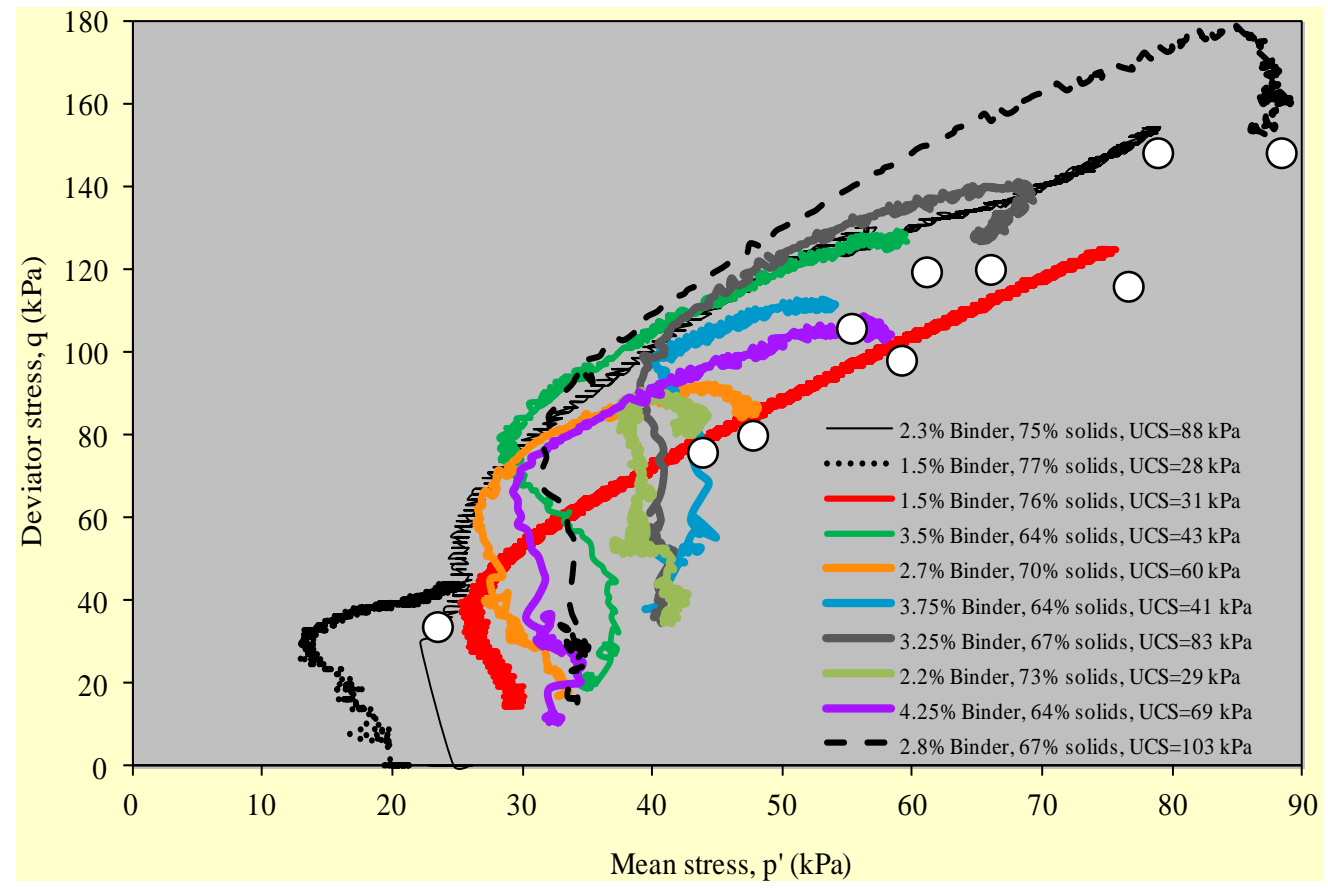

Figure 12 Stress path followed during consolidated undrained triaxial shearing of Wambo cemented specimens

\subsubsection{Rock mass support}

In addition to ensuring that the fill mass poses no risk to the underlying mining operations, it was also necessary to ensure that the paste material was able to fulfil the role of providing the necessary support to 
the overlying rock mass (i.e. to prevent 'sinkhole' formation). Specifically this requires that the fill mass does not deform excessively, through bearing failure or compression, upon loading from the rock mass.

Applying Tarzaghi and Peck's (1948) bearing capacity relationships, low density paste with a UCS of 30 and $50 \mathrm{kPa}$ was shown to be capable of supporting 25 and $35 \mathrm{~m}$ of failed rock, respectively, which was considered acceptable. Dense uncemented paste (i.e. that placed at a solids content in excess of $81 \%$ ) was shown to have a bearing capacity suitable for supporting over $100 \mathrm{~m}$ of failed rock.

To determine the impact of fill compressibility and incomplete tight filling the project rock mechanics engineers (Golder Associates 2013) combined the paste stiffness, as determined from triaxial testing, with the rock mass unravelling characteristics (swell factor, etc.) to estimate the permissible roof failure depth. Analysis showed that the combination of a $500 \mathrm{~mm}$ void between the fill surface and roof, i.e. incomplete tight filling, and a stiffness corresponding to paste with a UCS of $30 \mathrm{kPa}$ was expected to result in a maximum roof failure depth of approximately $2.25 \mathrm{~m}$. This was considered acceptable.

\subsection{Fill mix implementation strategy}

Considering the perceived variability in feed material and the need to control the paste rheological properties it was necessary to develop a paste fill operating strategy with flexibility. As described in the previous section, it was considered appropriate to target a paste target strength of $50 \mathrm{kPa}$, which provided a suitable factor of safety to account for variability. Based on the results of test work presented as part of this section the mix relationship set out in Figure 13 was established as an operating mix design framework. Superimposed over this mix relationship is the results of UCS test work (as presented in Figure 11) and the paste mixes that were shown to strain harden in $\mathrm{CU}$ triaxial testing are presented as white symbols.

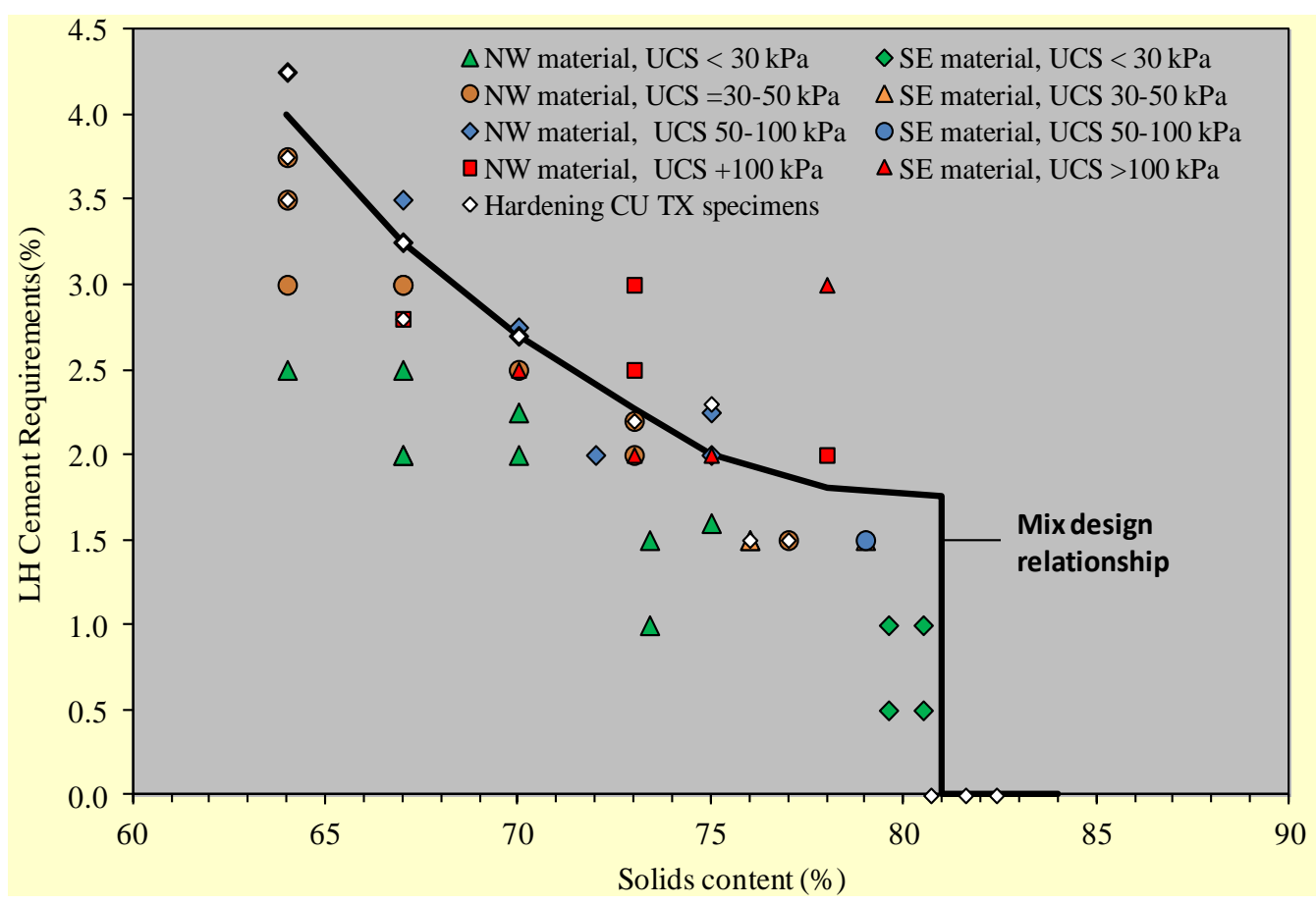

Figure 13 Wambo paste fill mix relationship

Based on past experience it is was expected that paste placed with a conical slump of 200-250 mm would deliver sufficient flowability, to achieve a suitable spread of material into the underground workings, while minimising segregation.

On this basis, the paste operating philosophy involved:

1. Adjusting the mixer water addition to achieve a slump within the desired range. 
2. Determine the operating solids content, based on the paste plant setpoint and Marcy scale measurements.

3. Adjusting the binder content based on the solids content and the mix relationship (Figure 13).

\section{$4 \quad$ Operational experiences}

\subsection{Introduction}

At the time of writing this paper approximately $70,000 \mathrm{~m}^{3}$ of paste has been placed. During this period the understanding of the process has developed considerably. The following section provides a summary of this experience, highlighting aspects of the project that proved to be successful as well as challenges that were encountered.

\subsection{Source material}

Peabody operate both an underground and open pit mining operation at Wambo and immediately prior to commencement of filling activities a modification to surface mining operations resulted in the, preferred, South-East region becoming unavailable for material extraction. However, due to underground mining it was necessary to commence filling activities as soon as possible. While it was not the preferred material source, filling operations commenced using alluvial material from the North-West area. As the system was designed to manage a range of material qualities this had little impact on the quality of paste produced. However, due to the high clay content, paste was manufactured at solids content towards the lower end of the range, covered by the operational framework (Figure 13). This resulted in the need to increase binder addition considerably (which was anticipated). However, the main impact of the unfavourable material was on paste production rates. While some minor reduction in productivity was expected this material caused a significant reduction in MISU processing rates and at times blinded the paste hopper screen leading to delays.

\subsection{Alluvial screening}

The single biggest challenge faced on the project to date was associated with the alluvial material screening process. As shown in Figure 4, the alluvial material contained significant portions of aggregate, which had to be removed. Due to the presences of unacceptable rocky material around the stockpile area and the desire to eliminate the construction of a hopper loading ramp, alluvial screening was undertaken using an excavator mounted MISU system.

While the paste production system was configured to produce paste in excess of $120 \mathrm{~m}^{3} / \mathrm{h}$, the high clay content of the alluvial material resulted in reduced MISU throughput rates, which directly impacted on plant feed rates. This issue was overcome by 'turning' stockpiled alluvial material (with loaders) in an effort to reduce the moisture content and sorting through the stockpiles to utilise the best available material source.

In an effort to quantify the impact of clay content on MISU production rates alluvial samples were collected at times for different MISU throughput rates. The Atterberg limits and moisture content of these samples were measured and used to determine the liquidity Index. Results available at the time of writing this paper showing the relationship between Liquidity index (LI) and MISU production rate are presented in Figure 14.

While the data presented in Figure 14 is limited, this shows a clear trend of increasing MISU rate with reducing $\mathrm{LI}$. This trend suggests that MISU throughput rates increase as the clay content and moisture content of the alluvial soils reduce, which is consistent with observations during operations. Quantifying this relationship provided a robust framework for the selection of suitable feed material for the second stage of filling operations. 


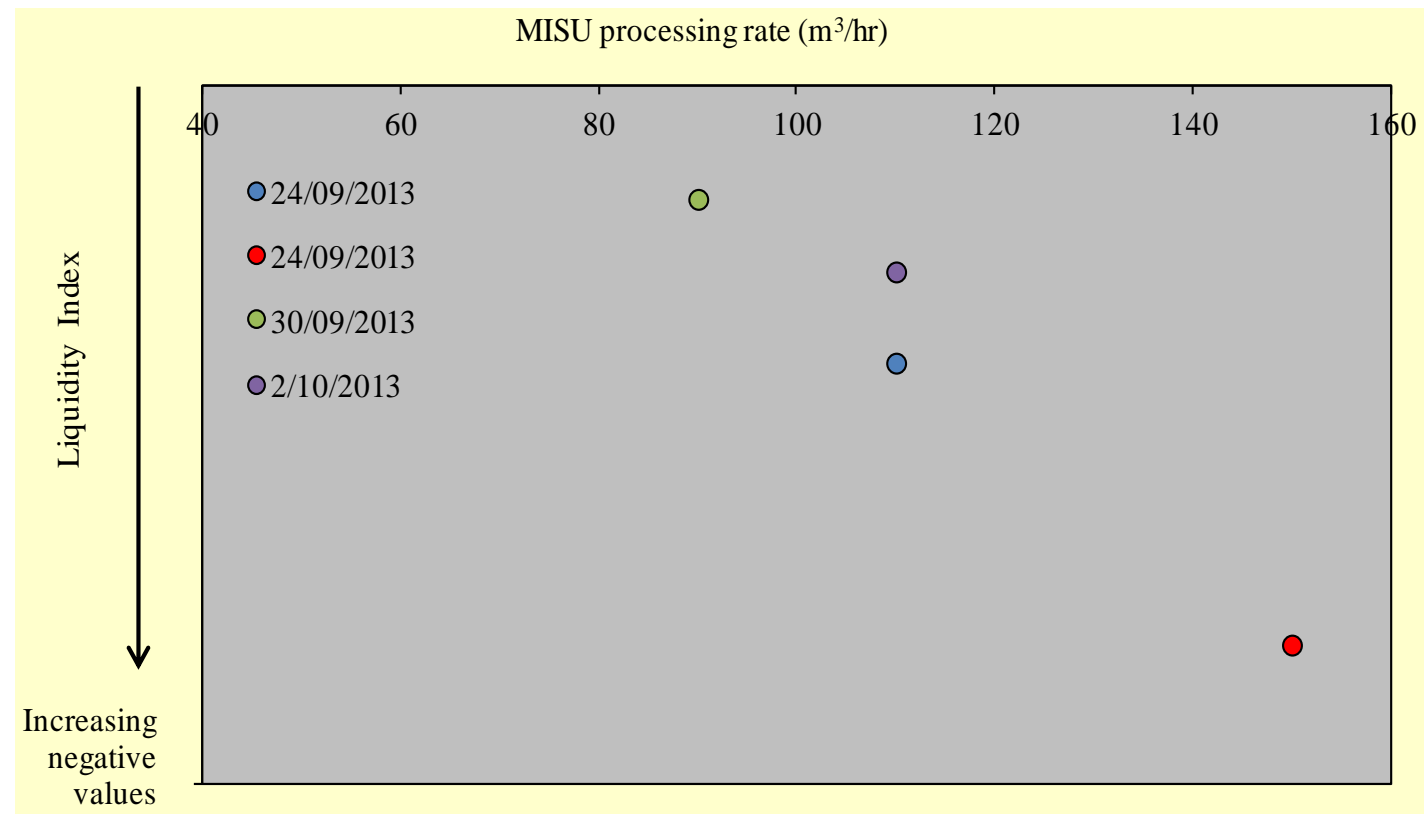

Figure 14 Trends between liquidity index and MISU throughput

\subsection{Quality control measurements}

Due to the nature of the feed material the continuous paste mixer was not completely breaking down all of the clay lumps. Furthermore, while the borehole lengths were quire short and vertical, it was recognised that the material would undergo additional mixing during transportation. This posed a challenge in terms of an appropriate means of preparing suitable quality control (QC) samples. To investigate the impact of additional 'lab scale' mixing of paste samples prior to rheological and strength QC testing, trials were undertaken using different mixing intensities and duration. The results are presented in Figure 15 and 16.

Figure 15 shows that the (higher shear rate) drill mounted mixer causes a much greater change in slump compared to equivalent paste mixed with the (lower shear rate) dough mixer. For both strategies the data shows that the paste rheological characteristics become relatively constant after five minutes of mixing.

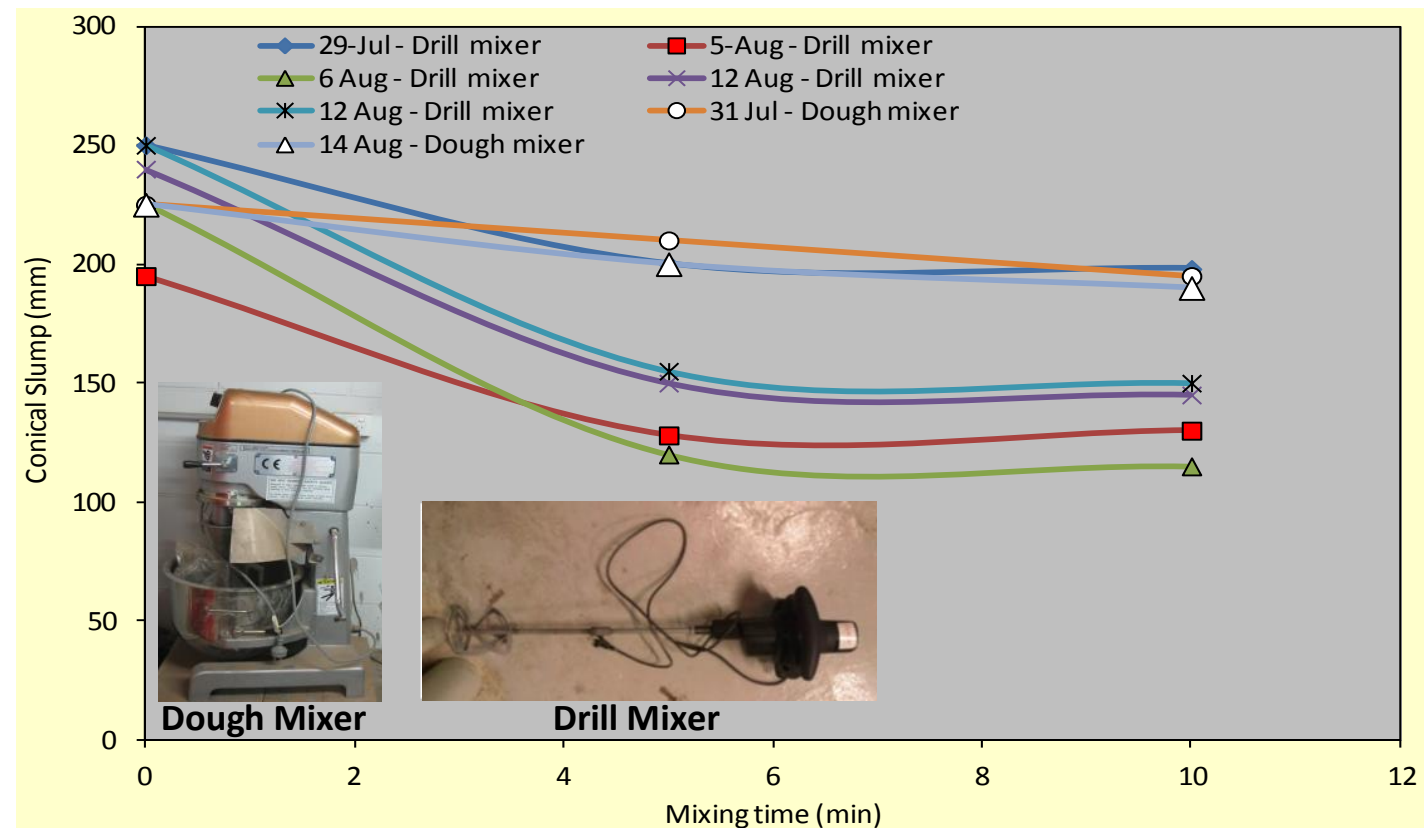

Figure 15 Conical slump against mixing time 
Figure 16 presents the strength measured for equivalent paste samples that were mixed, using either the dough or drill mounted mixer, for a period of five minutes prior to casting. This figure shows that paste specimens mixed using the (higher shear rate) drill mounted mixer generate considerably greater strength than equivalent specimens mixed using the (lower shear rate) dough mixer.

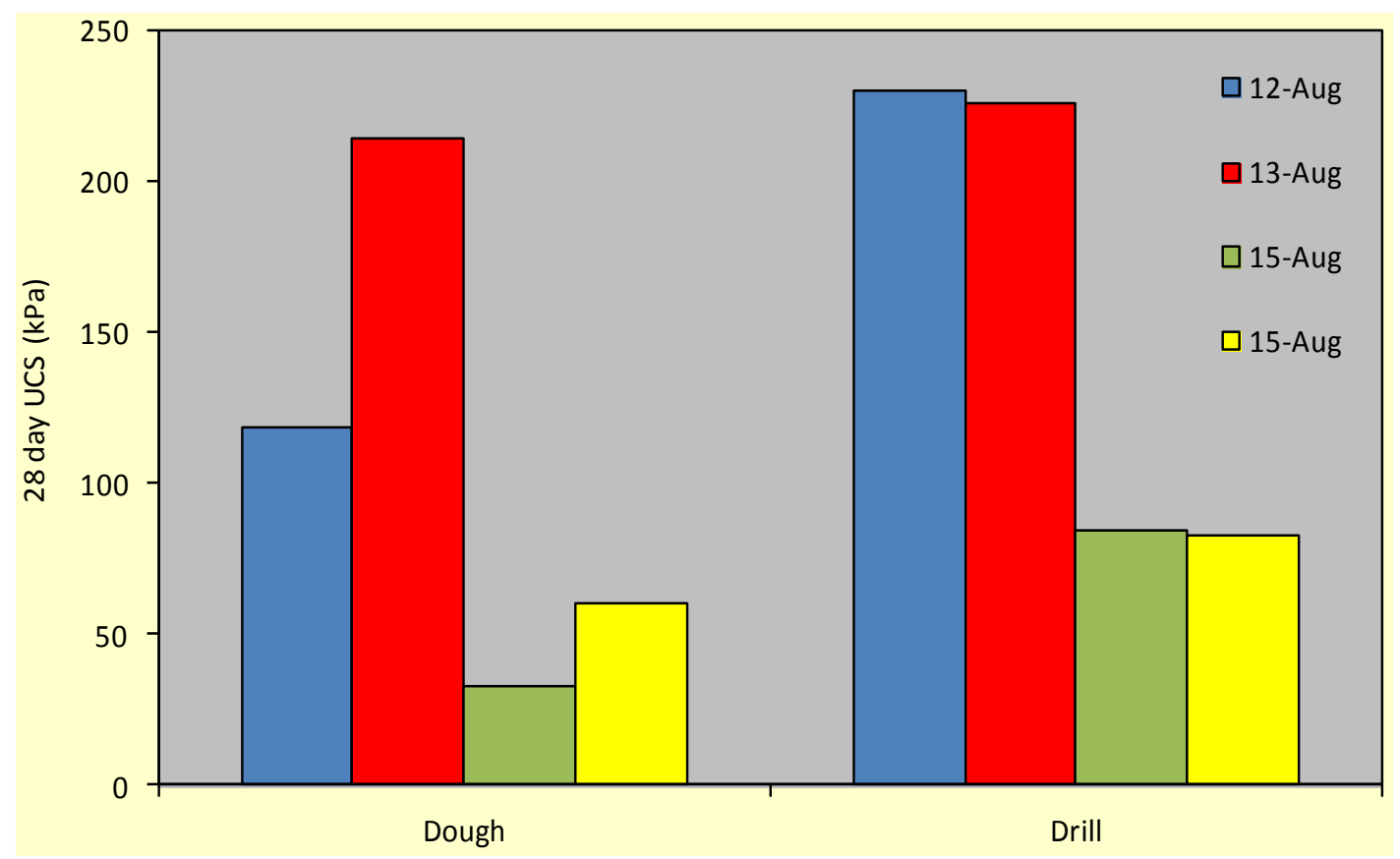

Figure 16 influence of mixing method on paste strength

Based on the results of this study, quality control specimens were prepared for testing by mixing the material for a period of five minutes using the dough mixer. This strategy was considered appropriate because it would improve the consistency of quality control measurements without excessively shearing the paste, which could potentially over estimate in situ strengths.

\subsection{Paste beaching}

As the objective of this project was to fill a large relatively flat array of drives, during the early stages of filling, attempts were made to understand how the paste rheological properties related to the ability to achieve the desired tight fill criteria. As no personnel access was permitted into the underground workings discrete borehole camera and depth measurements were used to gain an understanding of the paste flowability.

Limited survey points along the fill beach and the variable nature of the material made a correlation between paste slump and beach angle challenging. Data collected during the project is presented Figure 17. This figure shows the conical slump plotted against beach angle, where the horizontal distance between survey points varied from $30-70 \mathrm{~m}$. Cases plotted with a beach angle of zero correspond to situations where the drive was completely tight filled at the survey point.

While it is difficult to define a clear relationship, between beach angle and slump, Figure 17 shows a counter-intuitive trend of increasing beach angle with slump. Furthermore, these results indicate that, when deposited with a conical slump of $180-230 \mathrm{~mm}$, the material appears to flow quite favourably.

A possible explanation for the counter-intuitive trend may be that the high coarse aggregate content and low yield strength, of high slump paste, is creating some degree of segregation. This may be resulting in the deposition of coarser aggregates close to the deposition point and resulting in a localised barrier to further flows in that particular direction. 


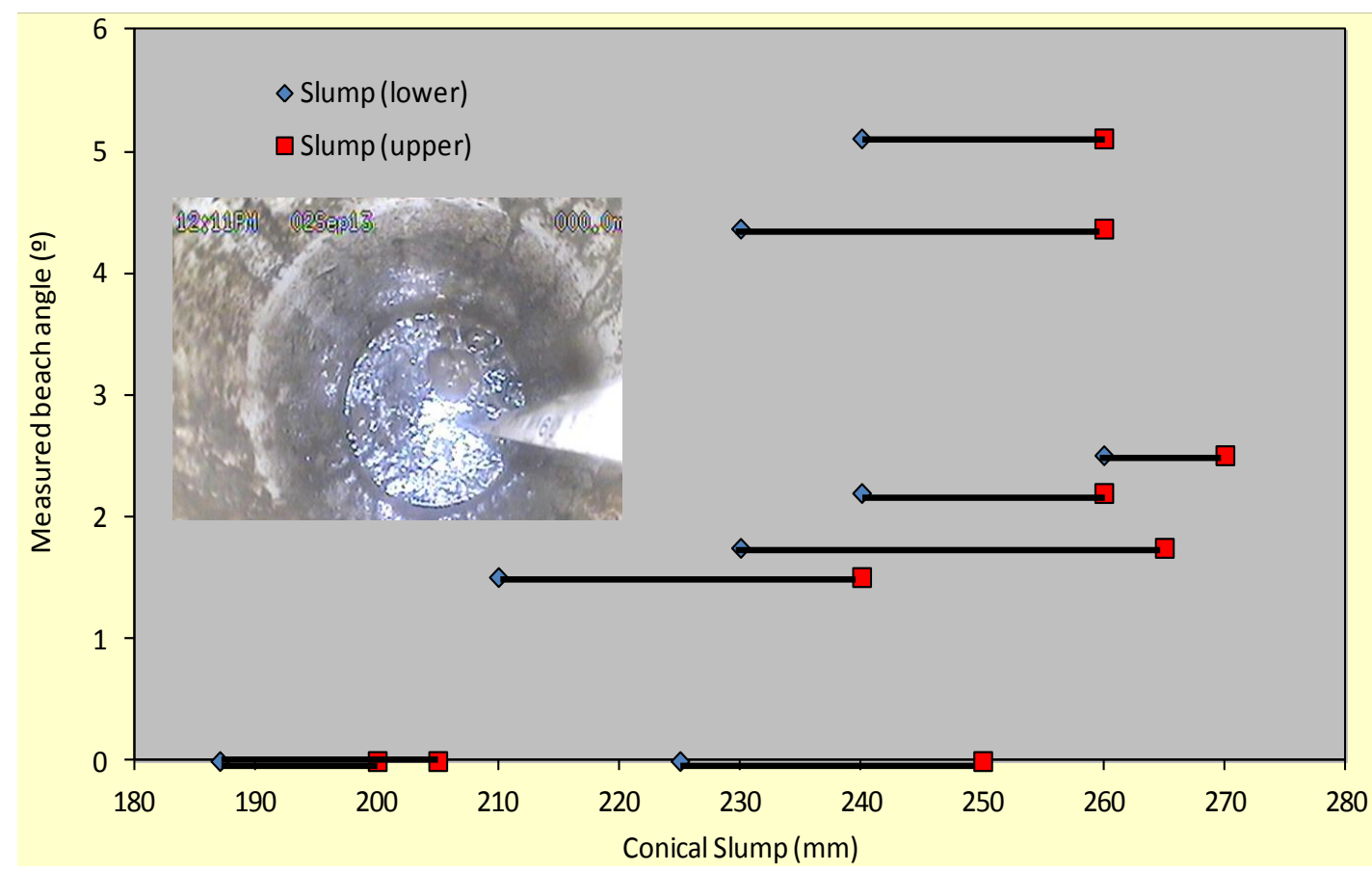

Figure 17 Measured conical slump against beach angle

\subsection{Paste quality control strengths}

The result from paste fill quality control testing is presented in Figure 18. With the exception of an increased binder dosage during the initial stages of filling, these paste mixes were batched in accordance with the mix design relationship presented in Figure 13. These results indicate that, while a reasonable amount of strength variability was observed, considering that the mix solids concentration varied by over $10 \%$ and the variability in alluvial material characteristics, the minimum $30 \mathrm{kPa}$ strength criteria was only marginally exceeded on most occasions.

Further reductions in binder content would almost certainly have resulted in significant portions of below specification strength and if a higher strength was targeted considerably higher binder content would have been necessary. For example should a minimum allowable strength criteria of $100 \mathrm{kPa}$ have been targeted (which is the industry standard for liquefaction resistance, based on Clough et al. 1989). Figure 11 suggests that approximately $25-50 \%$ more binder would have been required.

In this situation the poor quality of alluvials, used in paste production, resulted in the need to utilise the operational framework flexibility at the lower solids content range, resulting in a need to increase binder addition to achieve the desired quality. However, through an improved alluvial selection process it is hoped that future paste operations at Wambo can operate towards the upper (solids content) end of the framework, which would allow the required quality to be achieved while reducing the binder requirements. 


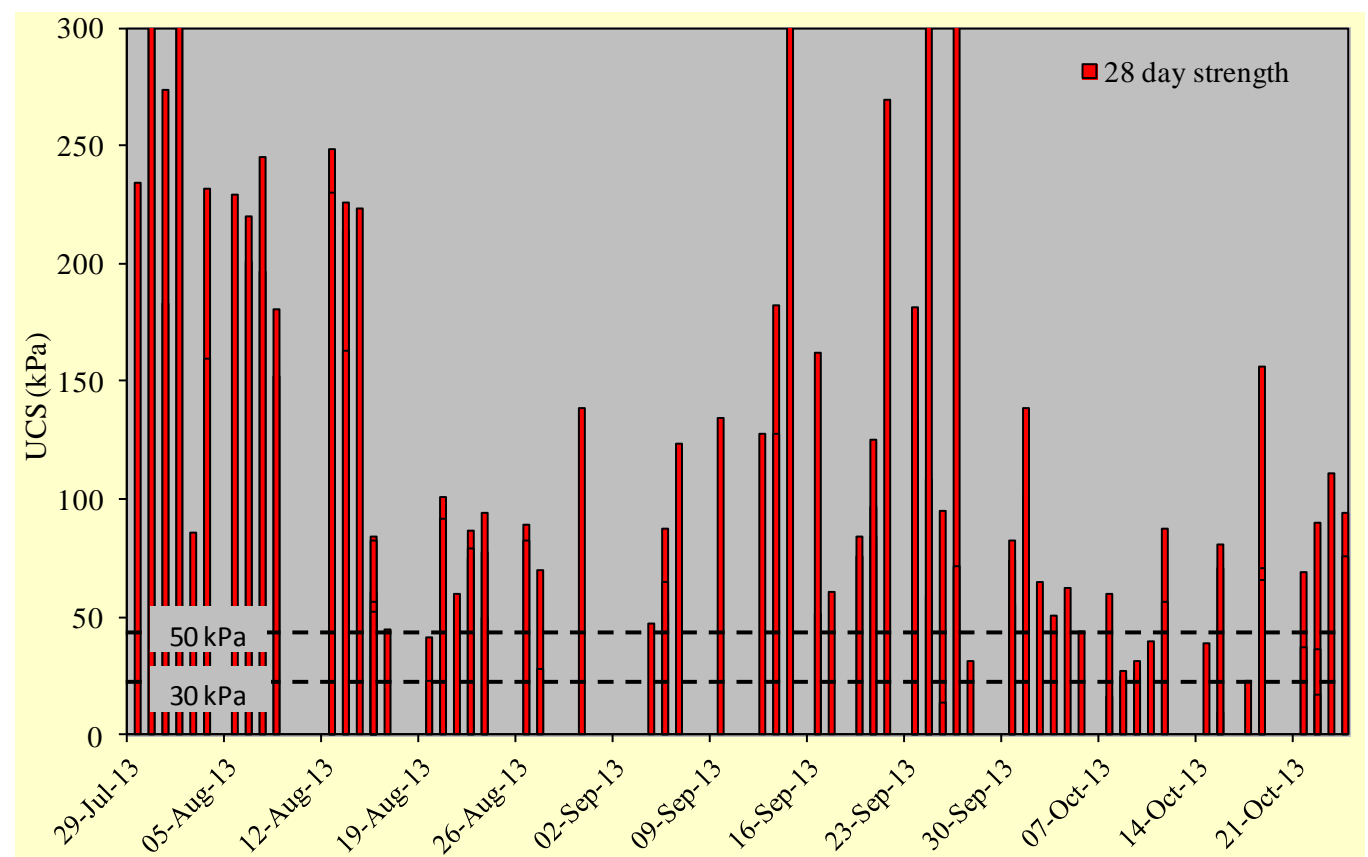

Figure 18 Results of paste fill strength $Q C$ testing

\section{Conclusion}

This paper presents a case study of a unique filling problem with unique feed material at the Wambo Coal Mine. Description of the fill system selection process, mix design strategy and field experience have demonstrated a number of key learnings. Specifically, this paper illustrates that:

- Careful consideration of the feed material and distribution requirements during the fill system design can deliver a robust filling strategy, even in cases where the material is variable and of poor quality.

- Comprehensive laboratory test work and analysis, which is specifically focused on the mechanical requirements if the material can deliver a cost effective, flexible mix design.

- Selection of suitable fill feed material has the potential to significantly impact on the productivity and cost effectiveness of filling activities.

- Drained direct shear testing proved to be a reliable method for identifying paste mixes that strain hardens under undrained shearing.

- A limited amount of available data indicates that MISU throughput rates can be related to liquidity index. Quantifying this relationship provides a definitive framework for future material selection.

- Post sampling mixing intensity and duration can significantly alter the rheological and strength of paste samples. Particularly when batching paste from 'dry' material, it is important to match the post sampling mixing intensity to the expected level of mixing downstream.

- The limited amount of data collected during filling operations suggests that an increase in paste slump may actually increase beach angles. This may be a consequence of segregation at higher slumps. Results show that favourable flowability can be achieved with conical slumps of 180-230 mm.

- A flexible fill mix design strategy allows the quality of the fill material to be maintained during times of variable material quality and variable rheological requirements. This was particularly important on this occasion, where mine production demands dictated the need to use unfavourable material at a late stage of the process. 


\section{References}

Been, K \& Jefferies, MG 1985, 'A state parameter for sands', Géotechnique, vol. 35, no. 2, pp. 99-112.

Clough, G, Iwabuchi, N \& Kuppusamy, T 1989, 'Influence of Cementation on Liquefaction of Sands', Journal of Geotechnical Engineering, vol. 115, no. 8, pp. 1102-17.

Fourie, AB, Blight, GE \& Papageorgiou, G 2001, 'Static liquefaction as a possible explanation for the Merriespruit tailings dam failure', Canadian Geotechnical Journal, vol. 38, no. 4, pp. 707-19, 10.1139/t00-112.

Golder Associates 2013, Report Number: 04-003-WBO-100, prepared by Golder Associates for Peabody Energy.

Kramer, SL 1996, Geotechnical Earthquake Engineering, Prentice Hall, Upper Saddle River, New Jersey.

Terzaghi, K \& Peck, RB 1967, Soil mechanics in engineering practice, John Wiley and Sons, New York, New York.

Zhang, H \& Garga, VK 1997, 'Quasi-steady state: a real behaviour?', Canadian Geotechnical Journal, vol. 34, no. 5, pp. $749-61$. 